University of Nebraska - Lincoln

DigitalCommons@University of Nebraska - Lincoln

The Nebraska Educator: A Student-Led Journal Department of Teaching, Learning and Teacher

Education

$10-4-2020$

Difficulty and Distance in Educational Encounters with Historical

Violence

Grant Scribner

University of Nebraska-Lincoln, grantscribner@huskers.unl.edu

Follow this and additional works at: https://digitalcommons.unl.edu/nebeducator

Part of the History Commons, and the Teacher Education and Professional Development Commons

Scribner, Grant, "Difficulty and Distance in Educational Encounters with Historical Violence" (2020). The Nebraska Educator: A Student-Led Journal. 51.

https://digitalcommons.unl.edu/nebeducator/51

This Article is brought to you for free and open access by the Department of Teaching, Learning and Teacher Education at DigitalCommons@University of Nebraska - Lincoln. It has been accepted for inclusion in The Nebraska Educator: A Student-Led Journal by an authorized administrator of DigitalCommons@University of Nebraska - Lincoln. 


\title{
Difficulty and Distance in Educational Encounters with Historical Violence
}

\author{
Grant Scribner \\ Department of Teaching, Learning, and Teacher Education \\ University of Nebraska-Lincoln
}

\begin{abstract}
This article reviews recent literature that addresses historical violence, difficult history, and the production of historical distance in teaching and learning about past violence. The author argues that based on the literature, the processes by which certain violent histories become "difficult" while others are aestheticized deserve greater attention. As violent histories become more or less difficult, the production of nuanced, contextually contingent historical distances may have serious implications for teachers' pedagogical decisions as well as students' reactions and understanding. The author argues further that historical violence not considered difficult or traumatic in a given moment and context deserves greater attention from scholars and researchers.
\end{abstract}

Keywords: violence, social studies education, history education, assessment, cognition

doi: 10.32873/unl.dc.ne003 
The presence of violence in history curriculum is peculiar. Educators face a pedagogical dilemma brought on by the sheer volume and ubiquity of violence throughout human history; it becomes simultaneously inescapable and easily avoided. In elementary and secondary schools-where brief, easily digestible narratives are prized--violence is generally deployed in one of two ways: as a catalytic, explanatory device for the movement of history, or as a whetstone for students to sharpen their capacities for moral judgment. In the first, violence is approached with analytical distance; it demonstrates cause-effect relationships, explains historical processes like the movement of peoples and technological development, bolsters defenses of the state, or pokes holes in the state's logic and tools. In the second, teachers use instances of violence to collapse historical distance through affective connection as they appeal to students' emotions or use historical violence as a filter for refining moral judgment. Missing from both approaches is a careful accounting for the relationship between teachers, violence in curriculum, and the process of creating and representing historical distances with students.

Whichever general approach is taken to accounting for violence, the terms of teachers' and students' encounters with it are by no means straightforward. The process of mediating violent pasts in the creation and enactment of curriculum present educators and students with both productive opportunities and potentially dire risks: to confront or avoid, to valorize or question, to understand violence as "difficult" and traumatic or to blithely subsume it within less troubling narratives. Decisions about whether and how to teach about violence animate much of the literature reviewed here, though it is necessary to understand from the outset that the complexities of these issues have led to a wide range of approaches from scholars with different concerns, vocabularies, and research agendas. The articles in this review have been selected, in part, because of their differences, which serve as a means of triangulating the various ways 
historical violence is mediated in curriculum enactment. The problem of violence in history is layered: it begins as an uneven process of historical inscription and distance in the creation of the archive and curriculum, then becomes an issue of intellectual and emotional understanding on the part of the teacher, and finally grows into a set of pedagogical dilemmas as the teacher attempts to engage violent histories with students.

The articles reviewed use a number of similar terms, though often with slightly different meanings and analytical ends in mind: "historical trauma," "violent pasts," "difficult history," and "difficult knowledge." I use the terms "historical violence" and "violent histories" as a means of maintaining focus on the presence of violence in the remembered past, regardless of its political or relational resonance. Many factors--sociocultural, historical, temporal--influence the degree to which a given event is understood to be difficult or traumatic, but my analytical interest falls in the space between violence understood to be "difficult" and violence treated as banal; both have serious implications for teachers and students as they create and interact with curriculum. I explore the relationship between historical violence and curriculum first by setting out "what makes difficult history difficult" (Gross \& Terra, 2018) and then weighing the contributions of scholarship on teaching about violent histories in three contexts: the relationship between historical thinking and violence (with particular attention to issues of recency, proximity, and historical distance), the relationship between teachers and violence in curriculum, and finally, pedagogical concerns and approaches used with students.

\section{Problems of Difficulty and Aestheticization}

In David Lowenthal's (2015) return to his seminal work on conceptions of history, The Past is a Foreign Country: Revisited, he argues that thinking about the past presents three potential "evils," two of which have conditioned how people understand and make use of past 
suffering: "the concomitant griefs that the grievous past saddles on the present...and the menace of its continuing potency" (p. 129). The degree to which these concerns become salient is historically contingent--it matters when one considers the past as well as which past is under consideration--an insight that has profound influence on the lines drawn by Gross and Terra (2018) around what makes difficult history difficult in a given context or moment. Their framework situates violence as one of five criteria necessary to qualify as difficult history, the other four being: centrality to the history of a nation; refuting "broadly accepted versions of the past or stated national values"; relevance to contemporary problems; and creating "disequilibria that challenge existing historical understandings" (p. 54). Gross and Terra argue that a particular type of violence, "usually collective or state sanctioned," often qualifies as difficult because "violence approved by the state or enacted by groups of supposedly upstanding citizens cannot be easily dismissed as aberrations or exceptions" (p. 54). Similarly, Zembylas and Bekerman (2008) argue that certain memories and forms of social remembrance become "dangerous" only when disruptive to the status quo, "the hegemonic culture of strengthening and perpetuating existing group-based identities" (p. 125).

Simon et al. (2000) offer a slightly different understanding of social remembrance pedagogies as either "strategic practice" or "difficult returns," both of which they find wanting. Strategic practice refers to "efforts to mobilize attachments and knowledge that serve specific social and political interests within particular spatiotemporal frameworks" (p. 3). The authors note that such efforts have been employed both in service of hegemonic nationalism and that "the remembrance of mass violence has sustained the demand for institutionalized practices of justice" based on an assumption that remembrance is ultimately oriented toward improving future conditions. The authors further argue that "on these terms, no matter how horrible its 
stories, a strategic remembrance of mass systemic violence is consolatory...[and] dependent upon a moralizing pedagogy" (pp. 3-4). Pedagogies of difficult returns? rest on a premise of "learning to live with a disquieting remembrance" that makes "the memorial impulse to turn and return traumatic history [into] an assignment, not simply a matter of choice" (p. 4). Simon et al. (2000) take issue with pedagogies of strategic practice because they privilege continuity by collapsing historical distance to reshape the violent past for contemporary political or social use. On the other hand, pedagogies of difficult return make unhelpful claims to continuity through "practices of identification that threaten to collapse differences across space/time and through performances of surrogacy" that heighten the risk of paralyzing the living in their traumatic remembrances (p. 5). The authors argue that both approaches ultimately fail to acknowledge adequately the "politics of relationality" between people and historical violence. Simon et al. (2000) offer a remedy by positing a third path: attending to historical violence through a process of "critical learning" that "enacts the possibilities of hope through a required meeting with traumatic traces of the past" (p. 5-7), a productive way to incorporate the strengths of the other two approaches without creating false continuity with historical violence.

The formulations of Simon et al. (2000), Zembylas and Bekerman (2008), and Gross and Terra (2018) make sense for filtering acts of historical violence through lenses of difficulty and trauma, but filtering historical violence on the basis of contemporary contextual resonance or state sanction implies that many—perhaps most—acts of historical violence that appear in curricula year after year may not qualify as "difficult" at a given moment. As Gross and Terra (2018) point out, If the difficulty of history is socially constructed, both outside the classroom and through the interactions of teachers and students with the curriculum, historical violence that is not deemed difficult may represent the majority of history curriculum in some contexts 
(particularly in teaching the history of the United States). With that in mind, it is troubling that the great weight of violence throughout history is understood to be (and taught as) untroubling. What, then, are the pedagogical implications of teaching about acts of violence that are not considered difficult or traumatic? Gross and Terra (2018) point out that "educators are sometimes reluctant to tackle...difficult histories in the classroom - and when they do, their instruction may be inadequate" (p. 52). It is unclear whether teachers avoid certain topics because they recognize their own practices as inadequate or simply because of the social discomfort of difficult histories. In either case, the questions remain about teachers' pedagogical decisions concerning the acts of violence they presumably present to their students that are not understood to be difficult. Does a teacher's discomfort with (or avoidance of) difficult historical violence imply greater sensitivity when she approaches less troubling moments of violence in curriculum? Or, does avoidance imply that a teacher might treat other acts of historical violence as completely unproblematic? A teacher's disposition toward the difficulty of certain events or histories would have profound effects on her pedagogical decisions and, in turn, students' reactions and learning. To limit our attention to "difficult" moments may obscure a broader view of the dispositions teachers adopt toward the majority of historical violence and the effects their dispositions may have on students' reactions and understanding.

Raudsepp and Zadora's (2019) analysis of teachers' sensitivity toward violence in World War II provides some evidence that it is necessary to give greater research attention to historical violence that is not considered difficult, or to the processes by which difficult historical violence becomes less so. Based on the open responses of 719 teachers from across Europe to an online questionnaire about their perceptions of the violence and atrocities of World War II, the authors argue: 
"The reasons for sensitivity [among teachers] were found to lie in cognitive and emotional barriers to treating the atrocities, violence and discrepancies between different perspectives on WW2 of social memory groups. A relatively new dimension, confirmed by the research, is the problem of the aestheticisation of the violent past. This can lead to banalisation and even legitimisation of the violence and aspects of the violence that pupils perceive to be fascinating" (p. 87).

While in many respects the findings fit neatly into Gross and Terra's framework of difficulty as conditioned by the nation state and perceived contemporary relevance, the problem of historical violence's aestheticization necessitates a closer examination of the processes and relationships that create the intellectual or emotional space (outside or beyond the state) for teachers and students to treat violence as either banal or legitimate. Helmsing (2014) provides useful theoretical grounding for considerations of affective connection in social studies education. He uses critical theory and feminist post-structural theory to argue that two affects present in curriculum materials and enactment—pride and shame — contribute to production of subjects in social studies education. One of Helmsing's examples, the textual and artistic production of affect in curricular materials through triumphant depictions of U.S. involvement in World War II, shows one common intersection of between teachers, students, historical violence, curriculum, and the state. While a textbook privileges a certain type of affective connection to violence in that instance, the dispositions of the teacher and students - the particular understandings of historical distance they each bring to the textual encounter-must also be investigated and carefully considered.

\section{Different Measures of Historical Distance}

In order to understand how teachers and students encounter historical violence in curriculum it is necessary to consider the nature of historical thinking about violence-in particular, the dynamic relationships between temporal distance, historical distance, and affective connection to the past. Phillips (2013) argues that temporal distance is "just the beginning, since 
historical understanding is inconceivable outside of the affective and ideological structures that make representation possible. Consequently, an idea so fundamental to the historical vocabulary might need to be rethought in more open and imaginative terms" (p. xi.). As a means of mediating these problems of distance, Phillips proposes the application of a heuristic framework that accounts for four distances: formal, summoning, affective, and conceptual. Phillips' heuristic attends simultaneously to the forms of historical representation, their affective claims, and the contemporary means of understanding upon which "history's intelligibility depends" ( $p$. 14). Klein (2017) argues that the complexities of interaction among these forces leads to "longer and shorter distancing in representations of the past," illustrating a need for an analytical framework "imagined as a continuum, where many intermediate positions and complicated combinations are possible, creating unique varieties of distance" (p. 184).

Raudsepp and Zadora's (2019) study provides a broad base of data that supports the arguments of Phillips and Klein. By framing the aestheticization of violence as problematic, Raudsepp and Zadora (2019) underscore the degree to which both historical and temporal distance influence students' affective connections when encountering the past; for the authors, the weakening affective connection over time is troubling, which implies that eliciting some sort of emotional reaction or affective connection from students is (or should be) a pedagogical goal for teachers. They describe the degree of affective connection between students and the atrocities of the Holocaust as "the regulation of emotions," which teachers relate to "the goal of moral education" (p. 103). The authors argue that students responding to the violence of the Holocaust with empathy and grief were understood to have taken the necessary lesson, while "indifference or fascination with the atrocities were understood [by teachers] to be indications of moral failure" (p. 103). 
These insights have particular explanatory power when applied to the shifting resonances of historical violence because the dynamics of historical distance-largely due to the uneven development of national projects and processes of social memory — had profound effects on the pedagogical decisions of teacher participants and the affective responses of student participants. Raudsepp and Zadora offer two speculative explanations for the banalization of historical violence. The first is socio-political context: one Arab Israeli teacher, for instance, identifies the Holocaust as a "sensitive issue" that needs to be taught, but argues that students' perceptions of the approved curricular materials as politically biased leads them "to become apathetic and discredit the claims of the material" (p. 101). The second explanation is that cultural change may alter the nature of students' interactions with the violent past: "The expansion of historical culture to the digital sphere provides young people with novel forms of engagement with historical events, such as, videogames" (p. 88).

The second explanation, while certainly plausible, is not fleshed out, which leads back to a broader assessment of the state of the research field. Laying out the trajectories of research on historical violence, Carretero (2017) nods to the affective and representational problems of historical distance in a call for more unified scholarly discourse:

As it can be easily imagined, it is not the same to teach, for example, the history of Roman Empire than to discuss in the classrooms about a national civil war that happened one or two decades ago. In this respect, most of the present advances on history learning and teaching have to do with how to teach and learn historical contents [sic]. On its part, most of the research on history textbooks has to do with what is included in the textbooks...[In] the area of research history education, and particularly in the field of the role of history education for conflict resolution and reconciliation, we need to establish a more meaningful relation between these two areas of research. (pp. 346-347).

Carretero (2017) does not explicitly address the issue of violence as bound up in the difficulties of historical distance (using "conflict" instead), but those issues certainly influence 
his argument for understanding and treating historical conflict in three separate contexts:

academic history, school history, and popular history. While the interactions of those three types of historical discourse condition teacher decisions and student reactions to violence, for Carretero the key to understanding the "difficulty" of violence is uncovering the relationship between individuals and the state, an argument echoed by Gross and Terra (2018).

As Carretero notes, textbooks provide an obvious intersection between history and the state; they are sites of mediating historical distance that also present a manageable evidence base for researchers. In one study of historical violence in textbooks, Brown and Brown (2010) use critical race theory and the concept of cultural memory to examine how racial violence in U.S. history is framed in twelve contemporary textbooks. They argue that the texts present violence against African Americans as both organized and often premeditated but also “deinstitutionalized acts undertaken by 'bad' men or 'bad' people" (p. 44). That insight leads the authors to argue:

"Although accounts of racial violence that historically have been excluded from textbooks are now being included, this inclusion matters little if it is presented in a manner that disavows material implications of racial violence on sustained White privilege and entrenched African American inequities" (p. 31).

If we apply Phillips's (2013) heuristic as a means of understanding further curricular implications of the texts' representations of historical violence, Brown and Brown's argument certainly attends to the affective and conceptual elements of historical distance. The violence in the textbooks studied is portrayed as brutal and unjust, collapsing affective distance for students; simultaneously, violence is assigned to "bad" individuals, widening the conceptual distance between injustice, organized violence, and the American state or American society. The resulting historical distance invites students to feel past violence keenly while directing any negative reactions or judgments toward individuals and away from the state and society. In that sort of 
historical representation the risks of affective connection--encounters that become traumatic for students--are outweighed by the potential social benefits of distancing historical violence from the contemporary state.

\section{Pedagogical Choices and Student Understanding}

In a similar vein, scholars and teachers have given attention to mediating historical violence through pedagogical decisions attempting to understand student reactions to their encounters with historical violence. Encounters with difficult knowledge have been framed productively as pedagogical and research dilemmas that are influenced by the past experiences of students and their relationships to the teacher/researcher. Psychoanalytic processes of uncovering offer one path toward understanding the dynamics of these interactions (Pitt \& Britzman, 2003; Collins, 2013), though as Gross and Terra (2018) note, it may be unrealistic to expect practicing teachers to also be experts in psychoanalysis. Concerns about temporal distance and spatial proximity of violence to students are also central to teachers' pedagogical decisions and their subsequent understandings of student reactions to historical violence. In studies of student encounters with recent historical violence teacher conceptions of temporal and spatial proximity to historical violence increased sensitivity to students' affective distance and influenced pedagogical decisions (Moyo \& Gonye, 2015; Lauritzen \& Nodeland, 2017). However, as Lauritzen and Nodeland (2017) note, students in one study appear to have internalized a different message than teachers had in mind; students described material support given by the school in the wake of relatively recent community violence, rather than reporting the emotional support teachers had attempted to embed in their own pedagogies. 


\section{Conclusion}

What should we make of these various conceptions of the relationship between historical distance, violence, and students' encounters with the past? Researchers have framed historical violence using assignations of difficulty based on shifting resonances, perceptions of moral obligation, and the agenda of the state (Gross \& Terra, 2018). Researchers have also argued for constructions of historical distance either as a continuum (Klein, 2017) or heuristic (Phillips, 2013) for understanding contemporary relationships to past violence. Affective connections to historical violence may be framed as a worthy pedagogical goal, moral obligation, or dire risk-the appropriate strength or weakness of those connections to be weighed differently in each case (Simon et al., 2000). With those connections in mind, researchers have pointed toward the emotional sensitivities of students and teachers as guides for pedagogical decision-making in ways that privilege recency, proximity, and past personal experiences/encounters (Pitt \& Britzman, 2003; Collins, 2013; Moyo \& Gonye, 2015; Lauritzen \& Nodeland, 2017). However, the risk of pinning constructions of resonant historical violence too closely to temporal recency-the aestheticization and banalization of more distant historical violence (Raudsepp \& Zadora, 2019) raises questions about how, or whether, researchers and teachers account for historical violence as it appears to become less salient or resonant. Does such violence simply recede from social memory? Does it become more pliable and easily shaped toward the ends of the state? In short, the dynamic process of seeing and confronting historical violence as difficult history, also a social and curricular process of forgetting--of easing the difficulty present in some historical violence. Such a process, as it plays out in the teaching and learning of history in schools, may deserve more careful attention. 


\section{References}

Carretero, M. (2017). The teaching of recent and violent conflicts as challenges for history education. In C. Psaltis, M. Carretero, \& S. Čehajić-Clancy (Eds.), History education and conflict transformation (pp. 341-377). Palgrave Macmillan.

Collins, A. (2013). Teaching sensitive topics: transformative pedagogy in a violent society. Alternation, 9, 128-149.

Gross, M. \& Terra, L. (2018). What makes difficult history difficult? Phi Delta Kappan, 99 (8), $51-56$

Helmsing, M. (2014). Virtuous subjects: A critical analysis of the affective substance of social studies education. Theory \& Research in Social Education, 42 (1), 127-140.

Klein, S. (2017). Preparing to teach a slavery past: History teachers and educators as navigators of historical distance. Theory \& Research in Social Education, 45(1), 75-109. DOI: 10.1080/00933104.2016.1213677

Lauritzen, S. M., \& Nodeland, T. S. (2017). What happened and why? Considering the role of truth and memory in peace education curricula. Journal of Curriculum Studies, 49(4), 437455. https://doi.org/10.1080/00220272.2016.1278041

Lowenthal, D. (2015). The past is a foreign country: Revisited. Cambridge University Press.

Moyo, N., \& Gonye, J. (2015). Representations of 'difficult knowledge' in a post-colonial curriculum: Re-imagining Yvonne Vera's The Stone Virgins as a 'pedagogy of expiation' in the Zimbabwean secondary school. Pedagogy, Culture \& Society, 23(3), 455-475.

Phillips, M.S. (2013). On historical distance. Yale University Press.

Pitt, A. \& Britzman, D. (2003). Speculations on qualities of difficult knowledge in teaching and learning: an experiment in psychoanalytic research. International Journal of Qualitative Studies in Education, 16(6), 755-776.

Raudsepp, M., \& Zadora, A. (2019). The sensitive scars of the second world war in teaching European history. Pedagogy, Culture \& Society, 27(1), 87-110.

Simon, R. I., Rosenberg, S., \& Eppert, C. (Eds.), (2000). Between hope and despair: Pedagogy and the remembrance of historical trauma. Rowman \& Littlefield Publishers, Inc.

Zembylas, M. \& Bekerman, Z. (2008). Education and the dangerous memories of historical trauma: Narratives of pain, narratives of hope. Curriculum Inquiry, 38(2), 125-54. https://doi.org/10.1111/j.1467-873X.2007.00403.X . 